\title{
Türkiye Su Ürünleri Üretimi ve Yeterlilik Endekslerinin Tahmini
}

\author{
Serhan CANDEMIR ${ }^{1 *}$, Murat DAĞTEKİN² \\ ${ }^{1}$ Doğu Akdeniz Geçit Kuşağı Tarımsal Araştırma Enstitüsü Müdürlüğü, Kahramanmaraş, Türkiye \\ ${ }^{2} \mathrm{Su}$ Ürünleri Merkez Araştırma Enstitüsü Müdürlüğü, Trabzon, Türkiye
}

* Sorumlu Yazar: serhan_candemir@hotmail.com

Geliş 10 Mart 2020; Kabul 07 Ağustos 2020; Basım 01 Eylül 2020.

Alıntılama: Candemir, S., \& Dağtekin, M. (2020). Türkiye su ürünleri üretimi ve yeterlilik endekslerinin tahmini. Acta Aquatica Turcica, 16(3), 409-415. https://doi.org/10.22392/actaquatr.700858

\section{Özet}

Bu çalışmada, Türkiye su ürünleri sektörü hakkında genel bir değerlendirme yapabilmek ve gelecek yıllara ait endeksler kullanılarak sektörünün incelenmesi ve sektörün geleceği hakkında yorum yapabilmek amaçlanmıştır. Bu amaç doğrultusunda, su ürünleri üretim ve dış ticaretinin 2000-2018 yıllarına ait zaman serisi verileri kullanılarak, gelecek 5 yıla (2019-2023) ilişkin öngörülerde bulunulmuştur. Su ürünleri üretiminde zaman serileri ile öngörüde bulunabilmek için çift üstel düzeltme yöntemi kullanılmıştır. Çalışmada, su ürünleri üretimine ilişkin Kendine Yeterlilik Oranı (KYO), İthalata Bağımlılık Oranı (İBO), İhraç Edilebilirlik Endeksi (IEEE) ve Kişi Başı Tüketim miktarı (KBT) endeksleri hesaplanmıştır. Yapılan öngörü sonuçlarına göre, su ürünleri avcıllk üretiminde azalmaların yaşanmasına karşın yetiştiricilik üretim miktarında artış yaşanacağı muhtemel görülmektedir. İthalat ve ihracat miktarlarında tahmin yıllarına ilişkin bir artış yaşanması ve ihracat miktarının artış oranının ithalat miktarına oranla daha yüksek gerçekleşmesi mümkün olabilir. Ayrıca, hesaplanan yeterlilik endeksleri sonuçlarına göre 2018 yılında \%112,9 olan kendine yeterlilik düzeyinin 2023 y1lında \%119,4'e ulaşması, ithalata bağımlılık düzeyinde ise önemli değişimlerin yaşanmayacağı tahmin edilmektedir.

Anahtar Kelimeler: Su ürünleri, çift üstel düzeltme, projeksiyon, yeterlilik

Estimation of Turkey Aquaculture Production and Proficiency Index

\begin{abstract}
In this study, we aimed to make an overall assessment of the fisheries sector in Turkey by using the indices for the next years and to make a comment about the future of the sector. For this purpose, forecasts for the next 5 years (2019-2023) have been made by using the time series data of 2000-2018 for fisheries production and foreign trade. Double exponential smoothing method was used in order to make predictions with the time series in fisheries production. In the study, SelfSufficiency Ratio (SSR), Import Dependency Ratio (IDR), Exportability Index (IE) and Per Capita Consumption (PCC) indices were calculated. According to the results of the forecasts, it is predicted that there will be an increase in the amount of aquaculture production, although there is a decrease in hunting. It may be possible that there will be an increase in the amount of imports and exports related to the forecast years and the rate of increase in the export amount will be higher than the import amount. In addition, according to the results of the calculated competence indexes, it is estimated that the level of self-sufficiency, which was $112.9 \%$ in 2018 , will reach $119.4 \%$ in 2023 , and there will be no significant changes in the level of dependency on imports.
\end{abstract}

Keywords: Aquaculture, double exponential smoothing, projection, qualification

\section{GíRiş}

Arkeolojik kalıntılar insanlığın ilk çağlardan itibaren yaşamsal faaliyetleri nedeniyle balık avcılığının ve yetiştiriciliği sonucunda elde edilen ürünlerin temel gıda olarak kullanıldığını göstermektedir (OKA, 2014). Fakat artan dünya nüfusu, teknolojik gelişmeler ve balıkçıllk pazarlamasının küreselleşmesi son dönemlerde av gücünde büyük artış meydana getirmiştir. (Anticamara vd., 2011). Nihayetinde dünyadaki birçok bölgede gelişen avcılık filoları doğal kaynaklar üzerinde aşırı av baskısının oluşmasını tetiklemiştir (Srinivasan, 2012; Watson vd., 2013). Bunun sonucunda 1980'lerin sonundan itibaren su ürünleri rezervi limitlerine ulaşarak küresel denizlerdeki av miktarında azalma ile sonuçlanmıştır (FAO, 2017). Yapılan değerlendirmelere göre dünya denizlerindeki balık stoklarının \%61,3'ü tamamen avlanmış, $\% 28,8$ 'i aşırı avlanmış ve sadece $\% 9,9$ 'u 
az avlanmış durumdadır (FAO, 2017). Sınırlı miktardaki av miktarından dolayı deniz balık avcılığının sürdürülebilirliğini tehdit eden ekolojik ve sosyo-ekonomik kayıplar yaşanmıştır. (Kelleher vd., 2009). Fakat sürekli azalan av miktarına rağmen küresel balık avlama gücü artmaya devam etmiş, sektör aşırı kapasite oluşumuna ve stokların aşırı tüketilmesine sebep olduğu bilinen ulusal yatırımlar ve teşvik politikaları ile ayakta tutulmuştur/sürdürülmüştür (Sumaila vd., 2010; Anticamara vd., 2011). Diğer yandan balıkçılık birçok ülkede, öncesinde yoğun bir eğitim gerektirmeyen bir girişim olarak kabul edildiği için ekonomik krizlerin etkisi ile artan işsizlik balıkçı sayısındaki artışla sonuçlanmıştır (FAO, 2018).

Dünyada deniz ve iç su avc1lı̆̆ toplam üretimi son yıllarda 90 milyon tonun üzerinde nispeten sabit bir seviyede seyretmekte; buna karşın su ürünleri yetiştiricilik üretimi sürekli olarak artmaktadır. Dünya su ürünleri üretimi 2016 y1lında 171 milyon ton olarak gerçekleşmiş; bu üretimin 90,9 milyon tonu $(\% 53,2)$ avcılıktan, 79,3 milyon tonu $(\% 46,8)$ yetiştiricilikten elde edilmiştir (FAO, 2018).

Yapılan bilimsel araştırmalara göre, önümüzdeki yıllarda su ürünlerine olan yatırımın daha da genişleyerek artacağı, 2030 yılında yetiştiricilik yoluyla elde edilen su ürünleri miktarının avcılıkla elde edilen su ürünleri miktarına eşit olacağı ve uzun vadede yetiştiricilik sektörünün avcılık sektörünü geçeceği tahmin edilmektedir (FAO, 2018). Bu da dünyadaki denizlerin ve iç suların önemini her geçen gün artırmaktadır. Su ürünleri yetiştiriciliğinin gelecekte potansiyeli yüksek bir sektör haline geleceği tahmin edilmektedir. Ancak, su ürünleri yetiştiriciliğinin sürdürülebilirliği için çevresel açıdan alınacak tedbirlerle su kaynaklarının korunması ve planlı kullanımı önemli ve gereklidir (FAO, 2018).

$\mathrm{Bu}$ çalışmanın amacı, Türkiye'de su ürünleri üretimi ve dış ticaretine dair öngörülerde bulunabilmek için çift üstel düzeltme yöntemi ile 2000-2018 yıllarına ait zaman serisi verileri kullanılarak gelecek 5 yıla (2019-2023) ilişkin projeksiyonlarda bulunmaktır.

\section{MATERYAL ve YÖNTEM}

$\mathrm{Bu}$ çalışmanın verileri Türkiye su ürünleri avcıllk ve yetiştiricilik üretimi, ithalatı ve ihracat miktarlarını kapsayan 2000-2018 yılları zaman serilerinden oluşmaktadır. Çalışmada kullanılan veriler Türkiye İstatistik Kurumu (TÜİK) veri tabanı ile Balıkçlık ve Su Ürünleri Genel Müdürlüğü istatistiklerinden alınmıştır. Veriler Minitap 17 istatistik paket programı ile analiz edilmiştir. Çift Üstel Düzeltme (Double Exponential Smoothing) yöntemi kullanılarak verilerin analizi yapılmıştır. Üstel düzeltme yöntemi geçmiş verileri matematiksel olarak düzeltmekte ve veri setindeki en son gözlem değerine yüksek, daha önceki verilere ise azalan oranlarda ağırlık vermektedir. Çift üstel düzeltme yöntemi ise belli bir trend içeren seriler için kullanılmaktadır (Yereli vd., 2012; Aydoğan vd., 2015; Uysal vd., 2016a; Çiçekligil ve Yazıcı, 2016). Bu yöntemle trend ortaya konularak üstel düzeltme yapılmaktadır. Bu yöntemde aşağıdaki eşitlik kullanılmaktadır (Uysal vd., 2016b):

Ortalama: $A_{t}=\propto Y_{t}+(1-\propto)\left(A_{t-1}+T_{t-1}\right)$

Mevcut Trend : $C T_{t}=A_{t}-A_{t-1}$

Ortalama Trend : $T_{t}=\beta C T_{t}+(1-\beta) T_{t-1}$

Tahmin : $\hat{Y}_{\mathrm{t}-1}=\mathrm{A}_{\mathrm{t}}+\mathrm{T}_{\mathrm{t}}$

Eşitliklerde $\mathrm{A}_{\mathrm{t}}$ : $\mathrm{t}$ döneminde seriye ait üstel olarak düzeltilmiş ortalamayı, $\mathrm{CT}_{\mathrm{t}}: \mathrm{t}$ dönemindeki mevcut trendi, $\mathrm{T}_{\mathrm{t}}: \mathrm{t}$ döneminde üstel olarak düzeltilmiş trendi, $\hat{Y}_{\mathrm{t}-1}:$ gelecek dönem için tahmini, $\propto$ : 0 ile 1 arasında değişen ortalamaya ait düzeltme faktörünü, $\beta: 0-1$ arasında değişen trend için düzeltme faktörünü ifade etmektedir.

Ayrıca, çalışmada 2019 - 2023 yılları arasında Türkiye balık üretimine ilişkin Kendine Yeterlilik Oranı (KYO), İthalata Bağımlılık Oranı (İBO), İhraç Edilebilirlik Endeksi (IEE) ve Kişi Başı Tüketim miktarı (KBT) gibi endeksler hesaplanmış olup, 2018 yılına ait hesaplamalar ve eşitlikler Tablo 1'de verilmiştir. 
Tablo 1. Türkiye balık üretiminde kendine yeterlilik endeksleri ve hesaplamaları

\begin{tabular}{llc}
\hline \hline Parametreler & Formülasyon & $\mathbf{2 0 1 8}$ yılı değerleri \\
\hline Üretim & Üretim = Avcıllı + Yetiştiricilik & 628631 ton \\
İthalat & & 100557 ton \\
İhracat & & 172412 ton \\
Tüketim & & 499461 ton \\
Kendine Yeterlilik Oranı (KYO) & KYO = Üretim/Tüketim & $\% 112,9$ \\
İthalata Bağımlılık Endeksi (İBE) & İBE = İthalat/Tüketim & $\% 18,1$ \\
İhraç Edilebilirlik Endeksi (İEE) & İEE = İhracat/Tüketim & $\% 31,0$ \\
\hline \hline
\end{tabular}

\section{BULGULAR}

\section{Türkiye Su Ürünleri Üretim Miktarı Tahminleri}

Bu çalışmada 19 yıllık (2000-2018) zaman serisi incelenmiş ve söz konusu zaman serisinde çift üstel düzeltme metodu ile tahmin yapılmıştır. Belirtilen zaman serisine ilişkin (KolmogorowSmirnow) normallik testi uygulanmış ve veri setinin normal dağılım gösterdiği tespit edilmiştir. Su ürünlerinde avcılık üretimi, yetiştiricilik miktarı, ithalat ve ihracat miktarlarına ilişkin zaman serilerine çift üstel düzeltme yöntemi uygulanarak 5 yıllık (2019-2023) tahminler yapılmıştır.

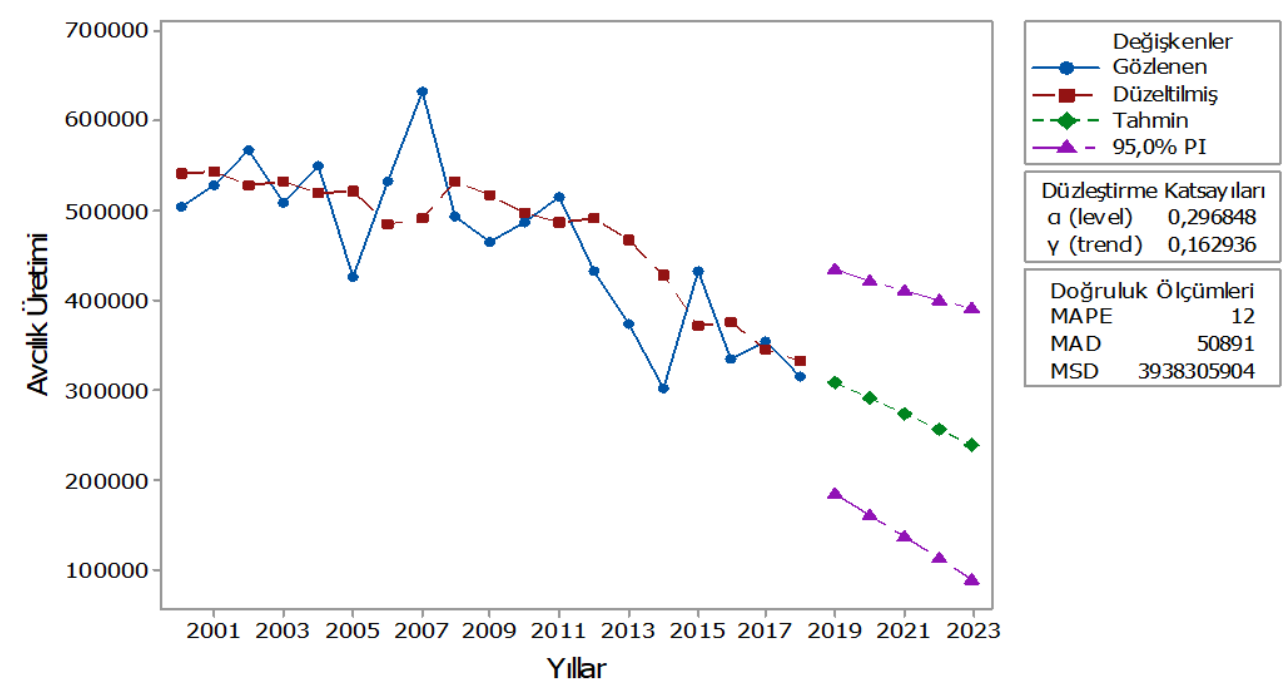

Şekil 1. 2019-2023 yılları arası su ürünleri avcılık üretim miktarı tahmini (ton)

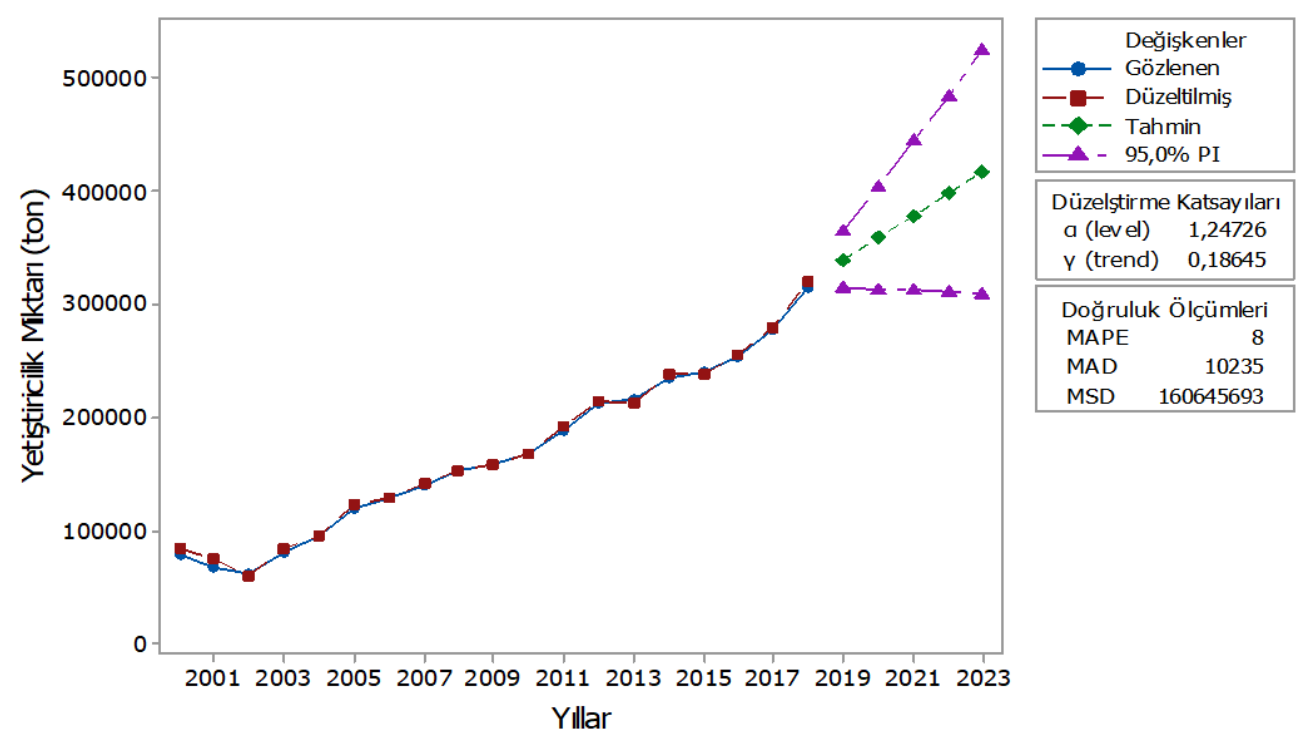

Şekil 2. 2019-2023 yılları arası su ürünleri yetiştiricilik üretim miktarı tahmini 
Toplam su ürünleri üretim içerisinde, avcılık yoluyla üretim miktarı incelendiğinde, gelecek 5 yıl içinde azalma eğilimi göstereceği tespit edilmiştir. Şekil 1 incelendiğinde, avcılık ile balık üretiminin her yıl artan oranlarda azalacağı gözlenmektedir. Avcılık ile balık üretiminin tam tersi bir durum olarak önümüzdeki 5 yıl içinde yetiştiricilikle ilgili olarak bir $\% 72$ oranında bir artışın yaşanması öngörülmektedir (Şekil 2). Türkiye 2018 yılı avcıllk ve yetiştiricilik balık üretim miktarları karşılaştırıldığında, her iki üretimin, üretim miktarlarının birbirine eşitlendiği ve 2019 yılı itibariyle makasın yetiştiricilik üretimi lehine açılacağı tahmin edilmiştir.

\section{Türkiye Su Ürünleri İhracat ve İthalat Miktarı Tahminleri}

Türkiye'nin gelecek 5 y1la ait, su ürünleri ihracat ve ithalat miktarları, 19 yıllık veri seti kullanılarak tahmin edilmiş ve sonuçlar Şekil 3 ve 4'de verilmiştir. 2019-2023 yılları arasında Türkiye su ürünleri ihracat ve ithalat miktarının artacağı öngörülmektedir. 2019-2023 yılları arasında Türkiye su ürünleri ihracat miktarında yaşanması muhtemel artışın yetiştiricilikten kaynaklanacağı tahmin edilmektedir. İthalat miktarında yaşanacak artışın ise Türkiye sularında avlanması ve yetiştirilmesi mümkün olmayan türlerden kaynaklanacağı söylenebilir. Nitekim ithalat miktarında yaşanması muhtemel artışın ihracat miktarında yaşanması muhtemel artıştan daha düşük olacağı tespit edilmiştir. Türkiye'nin 2018 y1lı ithalat-ihracat dengesi incelendiğinde su ürünleri diş ticareti, hem miktar olarak hem de değer olarak dış ticaret açığının azalmasında rol oynayacak düzeyde gelişme göstermiştir. Tahmin yıllarında da ihracat miktarının ithalat miktarına oranla daha yüksek düzeyde artacağı öngörülmektedir.

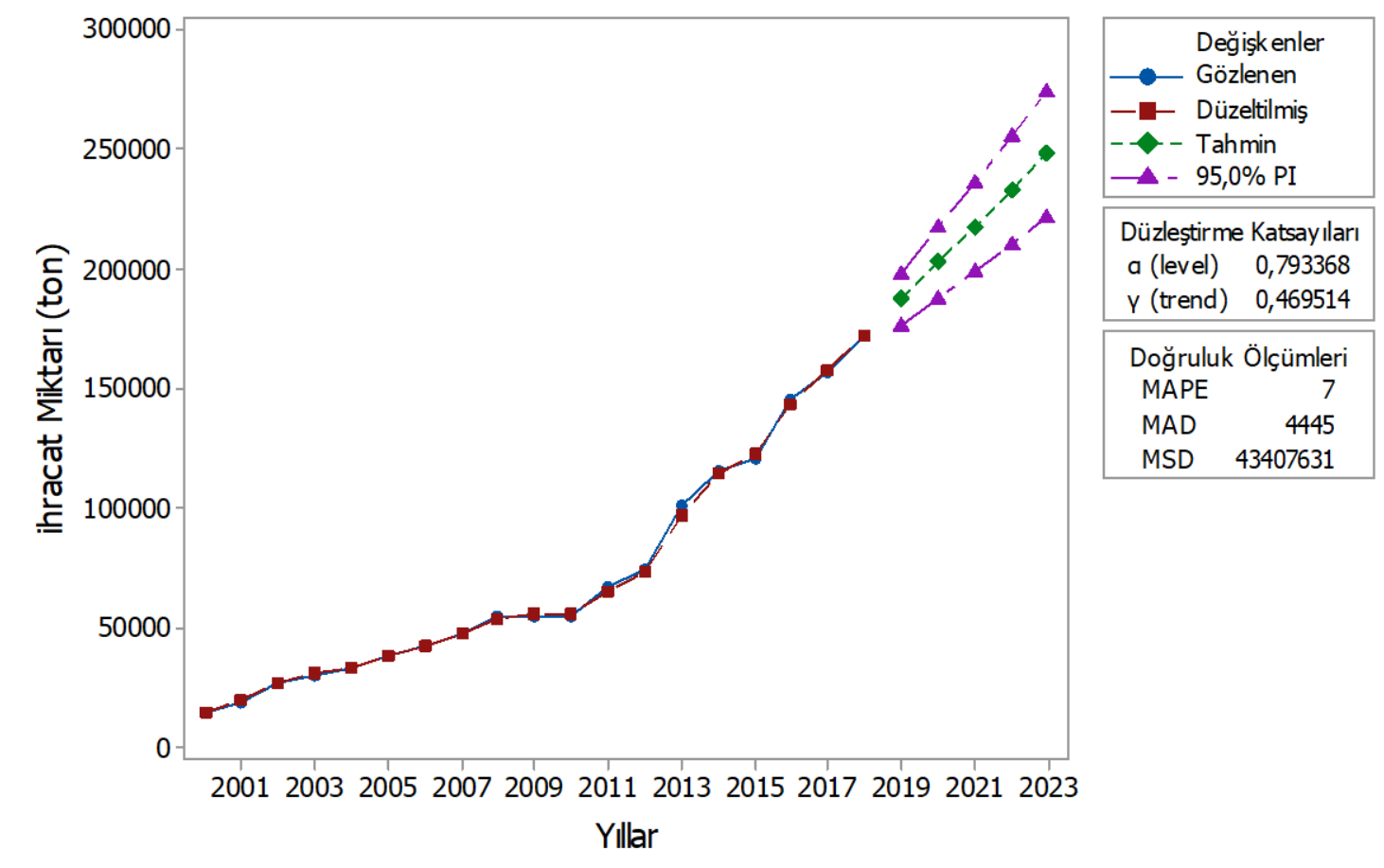

Şekil 3. 2019-2023 yılları arası su ürünleri ihracat miktarı tahmini 


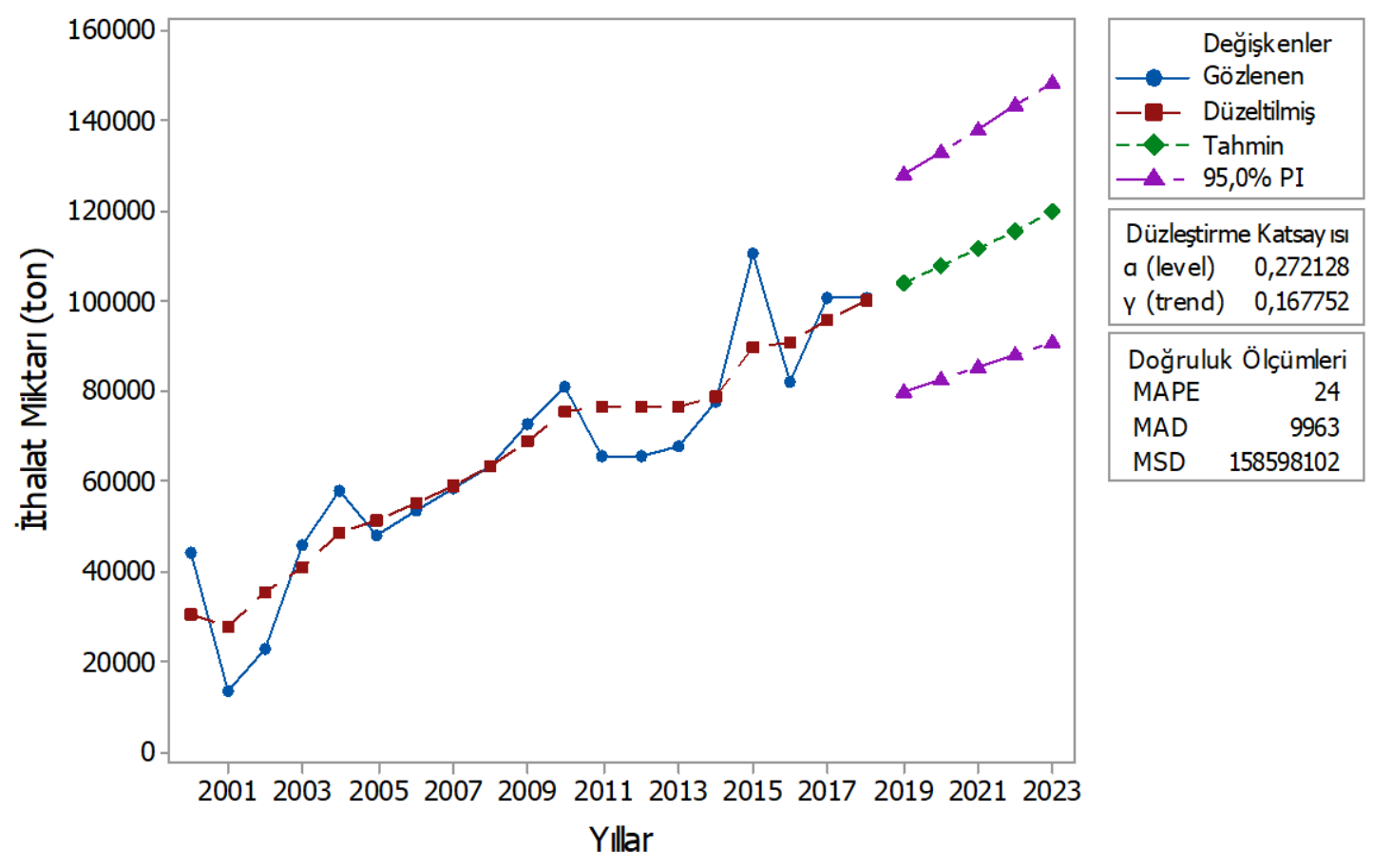

Şekil 4. 2019-2023 yılları arası su ürünleri ithalat miktarı tahmini

\section{Türkiye 2019-2023 Yıllarında Su Ürünleri Üretimi ve Dış Ticaret Tahminleri}

Türkiye su ürünleri üretimi, içerisinde avcılık ve yetiştiricilik üretimi olmak üzere ayrı ayrı tahmin edilmiş ve sonuçlar Tablo 2 'de verilmiştir. Su ürünleri yetiştiriciliği üretimi ve işleme teknolojilerindeki gelişmelere paralel olarak su ürünleri ihracatımızda önemli bir artış görülmektedir. 2000 yılından sonraki dönemde ihracat artışı devam etmiş, ithalat ise kısmen inişli çıkışlı, kısmen durağan bir seyir göstermiştir. 2018 yılında 314 bin ton olan avcılık üretiminin tahmin yıllarında azalarak 2023 yılında yaklaşık 240 bin ton seviyelerine düşmesi öngörülmektedir. Söz konusu düşüşün sebebi olarak iç ve deniz sularındaki kirlenme, yanlış ve yasak avlanma ve iklim değişikliğine bağlı su sıcaklığı değişimleri gibi faktörlerden kaynaklı olarak balık stoklarındaki azalma gösterilebilir. Avcılık üretimindeki sonuçların aksine yetiştiricilik üretim miktarı 2018 yılında 314 bin ton seviyelerinde iken yaklaşı \% $\% 0$ oranında artış göstererek 540 bin tona ulaşması öngörülmektedir. Tarımsal destekleme politikaları kapsamında uygulanan su ürünlerine yönelik politika araçlarının, yeni işletmelerin kurulmasını sağlayacağı ve buna bağlı olarak ise yetiştiricilik ile üretim miktarında artış yaşanacağı öngörülmektedir.

Tablo 2. 2019-2023 yılları arası su ürünleri üretimi ve dış ticareti tahmini

\begin{tabular}{lcccc}
\hline \hline & Avcllık (ton) & Yetiştiricilik (ton) & İhracat (ton) & İthalat Miktarı (ton) \\
\hline $2018^{*}$ & 314094 & 314537 & 172412 & 100557 \\
2019 & 309381 & 355768 & 187530 & 104647 \\
2020 & 291990 & 402395 & 202649 & 108737 \\
2021 & 274600 & 449023 & 217767 & 112827 \\
2022 & 257209 & 495650 & 232885 & 116917 \\
2023 & 239819 & 542278 & 248003 & 121007 \\
\hline *Gerçekleşen değerler
\end{tabular}

\section{Yeterlilik Endekslerinin Tahmini}

Ülkelerin kendine yeterliliğinin boyutunu ölçmek için Kendine Yeterlilik Oranı (KYO) ve İthalata Bağımlılık Endeksleri (İBE) kullanılmaktadır. Bu endekslerin ikisi de, bir ülkedeki toplam arzın ne oranda iç üretimden ya da ithalat yoluyla dışarıdan karşılandığını ölçmektedir. Bunlara ilaveten, 
üretimin ne kadarının ihraç edildiğini göstermek için de İhraç Edilebilirlik Endeksi (İEE) kullanılabilir (Dağtekin vd., 2019).

Türkiye su ürünleri sektörüne ilişkin olarak çalışmada kullanılan endeksleri incelemek, sektörün geleceği hakkında yorum yapabilmeye olanak sağlayacaktır.

Tablo 3. 2019-2023 y1lları arası yeterlilik endekslerinin tahmini

\begin{tabular}{lcccc}
\hline \hline & $\begin{array}{c}\text { Kendine Yeterlilik } \\
\text { Oranı (\%) }\end{array}$ & $\begin{array}{c}\text { İthalata Bă̆ımlılık } \\
\text { Endeksi (\%) }\end{array}$ & $\begin{array}{c}\text { İhraç Edilebilirlik } \\
\text { Endeksi (\%) }\end{array}$ & $\begin{array}{c}\text { Kişi başı Tüketim } \\
\text { Miktarı (kg) }\end{array}$ \\
\hline $2018^{*}$ & 112,9 & 18,1 & 31,0 & 6,1 \\
2019 & 114,2 & 18,0 & 32,2 & 5,8 \\
2020 & 115,6 & 18,1 & 33,7 & 5,7 \\
2021 & 117,0 & 18,2 & 35,2 & 5,5 \\
2022 & 118,2 & 18,4 & 36,6 & 5,4 \\
2023 & 119,4 & 18,5 & 37,9 & 5,3 \\
*Gerçekleşen değerler
\end{tabular}

Tablo 3'de 2019-2023 yılları için Türkiye su ürünleri sektörüne ilişkin bazı yeterlilik endekslerin sonuçları yer almaktadır. 2018 yılında su ürünlerinde Türkiye'nin Kendine Yeterlilik Oranı \%112,9 olarak hesaplanırken, 2019 yılında bu oran \%114,2 ve 2023 yılında artış göstererek \%119,4'e çıkacağ1 öngörülmüsşür. Bu sonuca ek olarak 2018 yılında \%18,1 olarak gerçekleşen İthalata Bağımlılık Endeksinin 2023 yılına kadar değişim göstermeyip \%18,5 civarında olacağ 1 tahmin edilmiştir. İthalata Bağımlılık Endeksi sonuçlarının aksine ihraç edilebilirlik endeksinde tahmin yıllarında artış olacağı öngörülmüş̧ür. 2018 y1lında \%31,0 olarak gerçekleşen endeks değerinin, 2023 yılında \%37,9'a yükseleceği tahmin edilmektedir. Avrupa da kişi başı balık tüketimi ortalama olarak $25-26 \mathrm{~kg}$ civarında iken (Congar, 2018) 2018 y1lında Türkiye'de kişi başı tüketimi 6,1 kg olarak hesaplanmış olup, 2023 yılına kadar kişi başına tüketimin azalarak 5,3 kg'a düşeceği öngörülmüştür.

\section{SONUÇ}

Türkiye su ürünleri üretiminin 2019-2023 yılları arasındaki durumunun tahmin edilmesinin, sektör için hazırlanacak politikalara 1şık tutacağı düşünülmektedir. Gelecek beş yıla ilişkin tahmini gerçekleştirilen üretim miktarları ve dış ticaret sonuçlarından hareketle Türkiye'nin yeterlilik endeksleri hesaplanmıştır. Türkiye'nin su ürünleri üretiminde kendine yeterlilik oranının tahmin yıllarında \%114,2 ile \%119,4 arasında gerçekleşecek olması Türkiye su ürünleri sektörünün gelecek yıllarda da gelişme ve büyüme trendine devam edeceğini ortaya koymaktadır. Ayrıca, 2018 yılında Türkiye'deki toplam su ürünleri arzının \%81,9'u iç üretimden karşılanırken 2023 yılında bu oranın $\% 81,5$ 'e gerileyeceği tahmin edilmiştir. 2018 yılında Türkiye su ürünleri ihraç edilebilirlik endeksi $\% 31,0$ olarak hesaplanmışken bu oranın 2023'de \%37,9'a yükselmesi ve bu sonuca ek olarak kişi baş1 su ürünleri tüketiminin azalması nedeniyle, Türkiye'nin sahip olduğu dış pazarları artırma veya yeni pazarlar bulma eğiliminde olması gerekliliğini ortaya koymaktadır. Bu sonuca ek olarak, Türkiye'de bireylerin sağlıklı beslenmesi adına kişi başı su ürünleri tüketimini artırıcı çalışmalarında yapılması gerekmektedir. Ayrıca su ürünleri yetiştiricilik ve işleme tesislerinin verimli bir şekilde kullanılabilmesi için ürün çeşitlendirilmesine gidilerek katma değeri yüksek üretim alanları teşvik edilmelidir.

Dünya su ürünleri dış ticaretinde, Türkiye önde gelen ülkelerden biri olma potansiyeline sahiptir. Bu potansiyele ulaşılabilmesi için uluslararası ticarette haksız rekabete yol açmayacak politika araçları ile sektörü desteklemesi ve markalaşma çalışmalarını yapması gerekmektedir. Ayrıca, Türkiye'de düşük olan su ürünleri tüketiminin artırılması için çalışmaların yapılmasının, sektörün büyümesine katkı sağlayacağı düşünülmektedir.

\section{KAYNAKLAR}

Anticamara, J. A., Watson, R., Gelchu, A., \& Pauly, D. (2011). Global fishing effort (1950-2010): trends, gaps, and implications. Fisheries Research, 107(1-3), 131-136.

Aydoğan, M., Demiryürek, K., \& Abacı, N.İ. (2015). Türkiye'de Kuru Fasulye Üretiminin Mevcut Durumu ve Gelecek Dönemler Üretiminin Tahmin Edilmesi. Türk Tarım-Gıda Bilim ve Teknolojisi Dergisi, 3(12), 962-968. 
Çelikkale, M.S., Düzgüneş, E., \& Okumuş, İ. (1999). Türkiye su ürünleri sektörü: potansiyeli, mevcut durumu, sorunlarl ve çözüm önerileri. İstanbul Ticaret Odası, Yayın No: 1999-2, İstanbul.

Congar, K. (2018). Balık Üretmeyen Türkiye Avrupa'nın Sekizinci Büyük Deniz Ürünleri Üreticisi, Euronews, Dünya.

Çiçekligil, Z., \& Yazıcı, E. (2016). Türkiye'de Tavuk Yumurtası Mevcut Durumu ve Üretim Öngörüsü. Tarım ekonomisi Araştırmaları Dergisi (TEAD), 2(2), 26-34

Dağtekin, M., Üstündağ, E., \& Candemir, S. (2019). Su Ürünleri Sektör Politika Belgesi 2019-2023. Tarımsal Araştırmalar ve Politikalar Genel Müdürlüğü, 132 s. Ankara.

FAO, (2017). Aquaculture Regional Reviews. In: FAO Fisheries and Aquaculture Department [online]. Rome. Updated 8 February 2017. www.fao.org/fishery/regional-aquaculture-reviews/en/

FAO, (2018). The State of World Fisheries and Aquaculture 2018-Meeting the sustainable development goals. Rome. Licence: CC BY-NC-SA 3.0 IGO.

Willmann, R., \& Kelleher, K., (2009). The sunken billions: the economic justification for fisheries reform (English). Agriculture and rural development Washington, D.C.: World Bank Group. http://documents.worldbank.org/curated/en/656021468176334381/The-sunken-billions-the-economicjustification-for-fisheries-reform

OKA, (2013). Orta Karadeniz Kalkınma Ajansı (OKA), (2013). Su Ürünleri ve Balıkçılık Sektör Raporu, Orta Karadeniz Kalkınma Ajansı, 39-85, Samsun https://www.oka.org.tr/assets/upload/dosyalar/su-urunlerive-balikcilik-sektor-raporu-39-85.pdf

Srinivasan, U. T., Watson, R., \& Sumaila, U.R. (2012). Global fisheries losses at the exclusive economic zone level, 1950 to present. Marine Policy, 36(2), 544-549.

Sumaila, U. R., Khan, A.S., Dyck, A. J., Watson, R., Munro, G., Tydemers, P., \& Pauly, D. (2010). A bottom-up re-estimation of global fisheries subsidies. Journal of Bioeconomics, 12(3), 201-225.

TÜİK, (2019). Türkiye İ́statistik Kurumu Veri Tabanı.

Watson, R. A., Cheung, W. W., Anticamara, J. A., Sumaila, R. U., Zeller, D., \& Pauly, D. (2013). Global marine yield halved as fishing intensity redoubles. Fish and Fisheries, 14(4), 493-503.

Uysal, H., Ağırbaş, N.C., \& Saner, G. (2016a). Türkiye'de Sofralık Üzüm Üretim ve Dışsatımına yönelik Projeksiyonlar ve Değerlendirmeler. XII. Tarım Ekonomisi Kongresi, 1293-1300, Isparta.

Uysal, O., Subaşı, O.S., \& Yaşar, B. (2016b). Türkiye Muz Üretim ve İthalatının Box-Jenkins ve Delphi Yöntemleri ile Tahmini. XII. Tarım Ekonomisi Kongresi, 1275-1282, Isparta.

Yereli, A.B., Selçuk, I.Ş., \& Köktaş, A.M. (2012). Kırgızistan Enerji Tüketim Projeksiyonu, http://ahmetburcinyereli.com/CP603.pdf 330-343 